\title{
Immunodeficiency-Centromeric Instability-Facial Anomalies Syndrome 1
}

National Cancer Institute

\section{Source}

National Cancer Institute. Immunodeficiency-Centromeric Instability-Facial Anomalies

Syndrome 1. NCl Thesaurus. Code C156430.

An autosomal recessive condition caused by mutation(s) in the DNMT3B gene, encoding DNA (cytosine-5)-methyltransferase 3B. It is characterized by immunoglobulin deficiency, centromeric instability of chromosomes 1,9, and 19 (rarely chromosome 2), and facial dysmorphism. 